\title{
Determination of the Critical Time of Fire in the Building and Ensure Successful Evacuation of People
}

\author{
Eduard Hulida1, Ivan Pasnak²*, Oleksandr Koval', Anatolii Tryhuba ${ }^{3}$ \\ 1 Department of Tactics and Rescue operations, Institute of Firefighting and Industrial Safety, \\ Lviv State University of Life Safety, \\ 79007 Lviv, Kleparivska str., 35, Ukraine \\ 2 Department of Vehicle Operation and Fire-Rescue Techniques, Institute of Firefighting and Industrial Safety, \\ Lviv State University of Life Safety, \\ 79007 Lviv, Kleparivska str., 35, Ukraine \\ ${ }^{3}$ Department of Project Management, Information Technologies and Telecommunications, Institute of Civil Defence, \\ Lviv State University of Life Safety, \\ 79007 Lviv, Kleparivska str., 35, Ukraine \\ *Corresponding author, e-mail: van-pas@ukr.net
}

Received: 27 June 2018, Accepted: 14 January 2019, Published online: 13 February 2019

\begin{abstract}
An engineering method was developed for determining the critical time of fire and determining the probability of evacuation of people from zone of fire, which makes it possible, with simplified dependencies, to quickly determine all the necessary factors in the evacuation process of people in case of fire in the building. To explain the use of the developed method, the sequence and example of determining the critical time of fire and determining the probability of evacuation of people from zone of fire for enterprise is considered. It was shown how one could calculate the time of evacuation of people from the premises from the zone of fire. The safety of people is provided when the time of evacuation does not exceed the time of the onset of the critical phase of the development of fire. For this purpose, the period for which the temperature, smoke density, oxygen concentration, hydrogen chloride, carbon dioxide and carbon monoxide gas reaches extremely dangerous values for a person was calculated. After determining all the necessary quantities, the probability of evacuation of people was analyzed in the absence of firefighting equipment in the building. The parameters determined by this new method are adequate and confirmed by other methods of calculation, in particular, developed by Hulida, Koval and FDS program. The relative error between the specified parameters does not exceed 8...12\% (in comparison with other mentioned methods).
\end{abstract}

\section{Keywords}

the critical time of fire, probability of evacuation, dangerous fire factors, evacuation of the people, fire in the building

\section{Introduction}

In the field of fire safety one uses the term "critical time of fire", that is, the time during which, from the moment of fire in a building, its dangerous factors reach the limit values for the life of a person who is in this building. The dangerous factors of fire include: 1) flames and sparks; 2) reduced concentration of oxygen; 3 ) toxicity of combustion products and thermal decomposition; 4) smoke; 5) increased temperature of the room in which the fire occurred.

From literary sources it is known that the critical time of fire depending on the volume of building is within $5 . .15$ min. During this time, there is a process of evacuating people from the premises in which a fire occurred. The evacuation process at enterprises is carried out under the leadership of the administration, and in the residential sector - under the leadership of the responsible persons. Of course, during this time, fire-rescue units still do not have time to arrive to the place of an emergency call and carry out the evacuation process in many cases. Therefore, the administration of the enterprise or responsible persons is responsible for the successful evacuation of people.

For the successful evacuation of people from the building during a fire, it is necessary for each volume of the building to know the value of the critical time of fire. When operational fire extinguishing plans are developed for various 
objects, the critical time of fire is not given. In the technical literature, the methods of calculation have already appeared to determine its value $[1,2]$, but these techniques are very complex and in most cases cannot be used in engineering practice. Therefore, there is a problem in the absence of simple engineering techniques for calculating the critical time of fire for any volume of premises with the possibility of using such a technique on various objects.

\section{Analysis of recent research and publications}

One of the first works, devoted to determining the length of time a possible stay of people in zone of fire from the appropriate concentration of oxygen and toxic substances, was [1]. Dependencies to determine the length of time a possible stay of people in zone of fire was obtained on the basis of the solution of the integral mathematical model of the initial stage of fire. The resulting dependencies are complex and difficult to use in engineering practice.

The next step to determine the length of time possible for people to stay in the fire zone was the integrated model of calculations of heat and mass transfer during a fire in the room and a differential model based on the use of differential partial differential equations describing the spatio-temporal distribution of temperatures, gas environment velocities in the building, concentrations of components of the gas environment, etc. On the basis of these models, application software packages were developed, with which it is possible to use a computer to investigate the processes of development of fire in the building. An example of such programs is the FDS [2], but using this program in engineering practice is a bit complicated.

Also worth considering SOFIE software suite [3]. This complex uses a mathematical model that includes: equation of continuity, three equations of pulse conservation along each coordinate, the energy conservation equation, the transport equation for the mass of the fuel pair and the mixing function, and also equation of $\mathrm{k}-\varepsilon$ model of turbulence corrected for the effect of natural convection. The combustion process was modeled using the Magnussen-Hjertager diffusion-vortex model. In connection with the implementation of the calculation of the safety assessment of evacuation of people (simulation is limited to the initial stage of the fire) to account for radiation heat transfer, a simplified $\chi_{R}$-model was used. Of course, this software package can be used in research, but not in engineering practice.

Worthy of note is the work [4], in which the author, based on the solution of the differential equations of the model in the investigation of fires, also determined its critical time. Undoubtedly, such an approach is rational, but it is difficult to use it for responsible persons for fire safety at the objects of protection.

An article [5] investigates the dynamics of pedestrian evacuation with the influence of the fire spreading. An extended floor field model is proposed. In the new model, the effect of fire on the evacuation is considered by introducing the fire floor field. The simulation results show that the number of pedestrians evacuated out of the room is highly related to both the original location of the fire and the configuration of the room. An extended floor field model [6] is proposed to simulate the pedestrian evacuation in a room by considering the smoke and fire effect under fire emergency. In this new model [6], the visibility floor field and temperature floor field are introduced, these extensions are important for evacuation simulations under fire circumstances. Through the numerical simulations, the influence of fire locations, type of burning materials, heat release rates and exit width on evacuation are analyzed.

The use of discrete design method to reduce the simulation time and cost in fire emergency evacuation simulations is proposed in [7]. This method is applied to an underground subway station to study the influence of different factors on fire emergency evacuation. In the paper [8] an evacuation experiment was conducted in a fire-protection evacuation walk in an underground market. Passing time, walking velocity, walking preference, and specific flux in the experiment are carefully analyzed. In the paper [9], one studies the agility of evacuation routes in relation to dynamically changing unpredictable hazardous conditions in smart space networks. Two new node importance metrics were proposed: evacuation betweenness centrality and evacuation centrality, both inspired by betweenness centrality. The simulation results [10] show that the pedestrian evacuation dynamics is highly related to fire location in the room and the spreading rates of the fire and the smoke.

The paper [11] presents an agent-based evacuation model with Smoke Effect and Blind Evacuation Strategy which respects some recommendation (evacuees should follow the boundaries of obstacles or wall to find the exits when their visibility is limited by smoke) by integrating a model of smoke diffusion and its effect on the evacuee's visibility, speed, and evacuation strategy. Also in this work the obtained simulation results on a realistic model of the supermarket confirm the important impact of smoke effect and blind evacuation strategy on the number of casualties. An intelligent Agent-Based Model enabling the modelling and simulation of evacuation of people from a building on 
fire was proposed in [12]. This proposed model is based on four parameters that allow her practical evaluation. A case study of simulation is carried out in a building having the general configuration of supermarket.

Also, the paper [13] presents an indoor fire evacuation model which enables a comprehensive representation of interacting essential variables, i.e. building environment, occupants and combustion products. GIS (Geographic Information System) technology has been applied in the model to analyze the distributions of the essential variables and support the modeling of human-fire interactions, which include human evacuation behaviors and fire gas hazards. In the article [14] to improve evacuation efficiency, an evacuation system was proposed based on GIS and Technology of IOT by analyzing the influence of smoke on evacuation.

The results of the analysis of the above works indicate that today, methods have not yet been developed that allow one to determine at the engineering level the critical time of fire and, accordingly, the length of time the possible presence of people in zone of fire. That is, it can be stated that development of this method is an actual problem, which was practically not paid attention.

\section{Statement of the problem and its solution}

The purpose of the work is to develop a methodology for determining the critical time of fire with the possibility of using it at the engineering level.

To achieve this goal, the following tasks must be solved:

1. determination of critical time of fire due to reduced oxygen concentration;

2. determination of the critical time of fire due to the increase of the concentration of toxic combustion products and thermal decomposition;

3. determining the allowable value of the optical density of smoke, taking into account the critical time of fire based on the data of the solution of the first two problems;

4. determination of the raised temperature of the volume of building within the limits of the allowable value taking into account the critical time of fire based on the data of the solution of the first three problems;

5. determination of the probability of evacuation within the critical time of fire.

At the first stage, one determines the critical time of fire $\tau_{c}$ from the reduced oxygen concentration. To do this, we take advantage of the recommendations of work [1], in which the dependence of the species is given
$\tau_{A . O_{2}}=\left\{\frac{3 c_{p} \rho_{0} T_{0} V}{\pi \eta(1-\varphi) Q_{\min } \psi_{s} v_{l}^{2}} \ln \left[\frac{\frac{c_{p} \rho_{0} T_{0} L_{1}}{(1-\varphi) Q_{\min }}+\rho_{01}}{\frac{c_{p} \rho_{0} T_{0} L_{1}}{(1-\varphi) Q_{\min }}+\rho_{1 c}}\right]\right\}^{\frac{1}{n}}, s,(1)$

where $c_{p} \approx 10^{3} \mathrm{~J} \cdot \mathrm{kg}^{-1} \cdot \mathrm{K}^{-1}-$ isobar heat capacity of the gas environment indoors; $\rho_{0} \cdot T_{0} \approx 3 \cdot 10^{2} \mathrm{~kg} \cdot \mathrm{K} \cdot \mathrm{m}^{-3} ; \mathrm{V}$ - volume of space for the spreading of combustion products, $\mathrm{m}^{3} ; \eta \approx$ 1 - coefficient of completeness of combustion; $\varphi$ - coefficient taking into account the absorption of heat by premises structures; $Q_{\min }$ - lowest heat of combustion, $\mathrm{J} / \mathrm{kg} ; \psi_{s}$ - specific rate of burnout, $\mathrm{kg} \cdot \mathrm{m}^{-2} \cdot \mathrm{s}^{-1} ; v_{l}$ - linear speed of development of fire, $\mathrm{m} / \mathrm{s} ; L_{1}$ - stoichiometric coefficient, which determines the amount of oxygen in $\mathrm{kg}$ required for combustion of $1 \mathrm{~kg}$ of combustible material; $\rho_{01}=0,27 \mathrm{~kg} /$ $\mathrm{m}^{3}$ - initial oxygen density in the building; $\rho_{1 c}=0,226 \mathrm{~kg} /$ $\mathrm{m}^{3}$ - critical oxygen density; $n=3$ - for circular development of fire; $n=2$ - for the linear development of fire.

Analyzing the constituent elements of Eq. (1), it was found that their large number are constant values. Therefore, one begins by considering the constituent elements of Eq. (1) on the coefficient $\varphi$, which takes into account the absorption of heat by the premises structures. Based on the research carried out in Lviv State University of Life Safety, the authors obtained the dependence on the effect of the duration of free development of fire on the value of the coefficient $\varphi$ (Fig. 1) for the closed premises.

Analyzing the dependence, which is presented in Fig. 1 , taking into account the existing data on the duration of the critical fire time within $5 \ldots 15 \mathrm{~min}$, we accept the value $\varphi$ for the average value $\tau_{c}=10 \mathrm{~min}$. In this case, $\varphi=0,25$.

The second element is $Q_{\min }$, the value is within the limits of $13800 \cdot 10^{3} \ldots 14900 \cdot 10^{3} \mathrm{~J} / \mathrm{kg}$ [4]. To enter the value of $Q_{\min }$ into Eq. (1) we assume an average value, that is $Q_{\min }$ $=14350 \cdot 10^{3} \mathrm{~J} / \mathrm{kg}$.

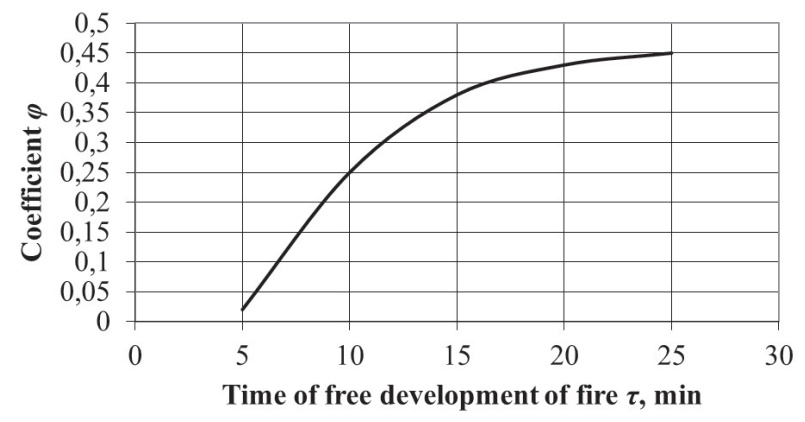

Fig. 1 Influence of the duration of free development of fire on the value of coefficient $\varphi$, which takes into account the proportion of heat flux passing into the enclosing structures 
The next element is $\psi_{s}$ - specific burning rate, $\mathrm{kg} \cdot \mathrm{m}^{-2} \cdot \mathrm{s}^{-1}$, the average value of $\psi_{s}=0,0245 \mathrm{~kg} \cdot \mathrm{m}^{-2} \cdot \mathrm{s}^{-1}$ [4]. The next element $v_{l}$ - linear speed of development of fire, $\mathrm{m} / \mathrm{s}$, which for the conditions under consideration is equal to $v_{l}=0,0125$ $\mathrm{m} / \mathrm{s}$. And the last element $L_{1}$ for given conditions is equal to $L_{1}=-1,437 \mathrm{~kg} / \mathrm{kg}$.

After substituting these components into Eq. (1), obtains the value of the critical time from the reduced oxygen concentration by a simplified dependence, which can be easily used in engineering practice:

- for circular development of fire

$\tau_{c . O_{2}}=\sqrt[3]{1442 V}, s$,

- for linear development of fire

$\tau_{c . O_{2}}=\sqrt{1442 V}, s$,

At the second stage, we determine the critical time of fire $\tau c$ due to the increased concentration of toxic combustion products and thermal decomposition. To do this, we take advantage of the dependence shown in [1]

$\tau_{c . t . p}=\left\{\frac{3 c_{p} \rho_{0} T_{0} V}{\pi \eta(1-\varphi) Q_{\min } \psi_{s} v_{l}^{2}} \ln \left[\frac{1}{1-\frac{(1-\varphi) Q_{\min }}{c_{p} \rho_{0} T_{0} L_{2}} \rho_{2 c}}\right]\right\}^{\frac{1}{\mathrm{n}}}, s,(4)$

where $L_{2}-$ a stoichiometric coefficient indicating the amount of toxic products released in $\mathrm{kg}$ per $1 \mathrm{~kg}$ of burning material; $\rho_{2 c}-$ the critical density of the relevant toxic product.

For buildings, the stoichiometric coefficients $L_{2}$ for the relevant hazardous fire factors have the following meanings: $\mathrm{CO}_{2}-L_{2 \mathrm{CO}^{2}}=0,203 \mathrm{~kg} / \mathrm{kg} ; \mathrm{CO}-L_{2 \mathrm{CO}}=0,0022 \mathrm{~kg} /$ $\mathrm{kg} ; \mathrm{HCl}-L_{2 \mathrm{HCl}}=0,014 \mathrm{~kg} / \mathrm{kg}$. The maximum allowable values of the partial density are as follows: $\mathrm{CO}_{2}-\rho_{2 c \mathrm{CO}^{2}}$ $=0,11 \mathrm{~kg} / \mathrm{m}^{3} ; \mathrm{CO}-\rho_{2 c \mathrm{CO}}=0,00116 \mathrm{~kg} / \mathrm{m}^{3} ; \mathrm{HCl}-\rho_{2 c \mathrm{HCl}}=$ $0,000023 \mathrm{~kg} / \mathrm{m}^{3}$.

The critical time of fire due to the increase of the concentration of toxic combustion products and thermal decomposition is determined by the simplified dependencies:

- for circular development of fire

$$
\tau_{c . t . p}=\sqrt[3]{6794 V \cdot \ln \left(\frac{1}{1-\frac{35,9}{L_{2}} \rho_{2 c}}\right)}, s,
$$

\footnotetext{
- for linear development of fire
}

$\tau_{c . t . p}=\sqrt{6794 \mathrm{~V} \cdot \ln \left(\frac{1}{1-\frac{35,9}{L_{2}} \rho_{2 c}}\right)}, s$.

If a negative number is obtained under the logarithm, then this dangerous fire factor is not a threat. To determine $\tau_{c}$, a negative sign is necessary replace the numbers with positive ones. For example: when one has $\ln (-x)$, one uses $\ln (x)$.

At the third stage, we determine the smoke of the building due to changes in the optical density of smoke $\mu$. To do this, it is necessary to determine the critical times of fire by concentration of oxygen and the concentration of all possible toxic products. After that, set the lowest value of time in seconds, which is obtained according to Eq. (2) or Eq. (3) and Eq. (5) or Eq. (6) according to the type of development of fire. According to the smallest value $\tau_{c}$, to determine the magnitude of $\mu$ by the dependence [15]

$$
\mu=\frac{c_{p} \rho_{0} T_{0} D}{Q_{\min } \eta(1-\varphi)}\left[1-\exp \left(-\frac{\psi_{s} S_{F} \eta Q_{\min }(1-\varphi)}{c_{p} \rho_{0} T_{0} V} \tau\right)\right], \mathrm{Np} \cdot \mathrm{m}^{-1}
$$

where $D=270 \mathrm{~Np} \cdot \mathrm{m}^{2} / \mathrm{kg}$ - specific smoke; $S_{F}$ - equals $0.25 \alpha v_{l}^{2} \tau^{2}, \mathrm{~m}^{2}$ - area of fire; $\alpha$ - corner of development of fire, rad; circular fire $360^{\circ}$ [ $\alpha=3,14 \mathrm{rad}$ ], angular fire $180^{\circ}$ $[\alpha=1,57 \mathrm{rad}]$; angular fire $90^{\circ}[\alpha=0,785 \mathrm{rad}] ; \tau$ - the smallest value of the critical time of fire $\tau_{c}$, s.

After substituting in Eq. (7) all stable elements, we obtain a simplified dependence for determining the optical density of smoke

$\mu=7,5\left[1-\exp \left(-\frac{3,5 \cdot 10^{-5} \alpha \tau^{3}}{V}\right)\right], \mathrm{Np} \cdot \mathrm{m}^{-1}$.

The value of the optical density of smoke should be $\mu_{i} \leq$ $1,2 \mathrm{~Np} / \mathrm{m}$. In case where the optical density of smoke will be $\mu_{i}>1,2 \mathrm{~Np} / \mathrm{m}$, then it is necessary to reduce this time to ensure the above condition and only then take the value $\tau_{c}$.

At the fourth stage, one determines the heating temperature of the building from fire using the lowest value of $\tau_{c}$ and the dependence for the standard temperature regime

$t=\left[345 \cdot \lg \left(8 \tau_{c}+1\right)\right] k+t_{0},{ }^{\circ} \mathrm{C}$,

where $\tau_{c}$-duration of fire within the critical time, min; $t_{0}$ - temperature in the building before the fire (at calculations $t_{0}$ take $20{ }^{\circ} \mathrm{C}$ ), ${ }^{\circ} \mathrm{C} ; k=0,06 \ldots 0,07$ - the coefficient whose value is obtained on the basis of the results 
of experiments, and which takes into account the distribution of heat from the center of fire at its initial stage by the building at an altitude of up to $2 \mathrm{~m}$ from the floor. The value of $t$ on the aisles should not exceed $70^{\circ} \mathrm{C}$. In the case when $t$ exceeds $70{ }^{\circ} \mathrm{C}$, it is necessary to reduce $\tau_{c}$.

From all specified times, it is necessary to select the smallest value which will correspond to $\tau_{c}$. The results of the analysis of temperatures at the initial stages of fires in the buildings showed that at a distance of $10 \ldots 18 \mathrm{~m}$ from the center of fire, the temperature of the air at a height from the floor to $2 \ldots 2,5 \mathrm{~m}$ for $10 \ldots 15$ minutes from the beginning of the fire is less than $70{ }^{\circ} \mathrm{C}$.

At the fifth stage, one turns to the determination of the probability of evacuation $P_{e}$ of victims from zone of fire

$P_{e}=1-\left(1-P_{e . n . i}\right)\left(1-P_{e . a . j}\right)$,

where $P_{\text {e.n.i }}$ - probability of evacuation of people who are located in the building in $i$-zone, by evacuation routes in case of fire; $P_{e . a . i}$ - probability of evacuation of people from $i$-zone due to emergency exits or with other means of salvation (in the absence of data $P_{\text {e.a. }}$ it is allowed to take 0,03 in the presence of emergency exits or means of salvation and 0,001 - in their absence).

Probability of evacuation of people $P_{e, n . i}$ with using evacuation routes from zone of fire are determined by dependence

$P_{e . n . i}=\frac{0,8 \tau_{c}-\tau_{e . V}}{\tau_{n . S . V}}$,

where $\tau_{e . i}$ - time of evacuation from $i$-zone, $\min ; \tau_{\text {n.e. }}$ - time from the beginning of fire to the beginning of evacuation, $\min$ (if there is a fire warning system in the building, $\tau_{\text {n.e.i }}$ takes equal time with the system's operation taking into account its inertia, that is $1 . .2 \mathrm{~min}$; in the absence of fire and anti-smoke alert systems, as well as evacuation management systems for people $\tau_{\text {n.e. }}=3 \ldots 5 \mathrm{~min}$ for the first floor of fire and $\tau_{\text {n.e.i }}=6 \mathrm{~min}$ for higher floors [16]).

Time of evacuation from i-zone is determined by dependence

$\tau_{e . i}=\sum_{j=1}^{m} \tau_{e . j}+\tau_{d . i} ;$

$\tau_{e . j}=\frac{l_{e . j}}{k_{e} V_{e . j . r}}$,

where $m$ - total number of $j$-areas in $i$-zone; $\tau_{e, j}$ - time of evacuation from $j$-area, which does not overlap with another evacuation time acting simultaneously, $\min ; l_{e, j}-$ length of evacuation path from $j$-area, $m ; k_{e}$ - number of evacuation exits; $V_{\text {e.j.r }}$ - actual average speed of evacuation from $j$-area, $\mathrm{m} / \mathrm{min} ; \tau_{d . i}$ - duration of movement delay in $i$-zone as a result of the accumulation of people at the border of transition from $i$-zone to $(i+1)$-zone

$\tau_{d, i}=n_{i} S\left(\frac{1}{q_{e(i+1)} b_{e(i+1)}}-\frac{1}{q_{e . i} b_{e . i}}\right) ;$

$S$ - average area of horizontal projection of a person, $\mathrm{m}^{2}$ (for calculations accept $\mathrm{S}=0,125 \mathrm{~m}^{2}$ ); $q_{e . i}$ - intensity of movement in $i$-zone, $\mathrm{m} / \mathrm{min} ; b_{e . i}$ - the width of the evacuation passage or the door at the exit from $i$-zone, $\mathrm{m} ; q_{e(i+1)}$ - intensity of movement in $(i+1)$-zone, $\mathrm{m} / \mathrm{min}$ (for calculations accept $q_{e(i+1)}=8,5 \mathrm{~m} / \mathrm{min}$ for the density of human stream $\left.D_{e . i}=0,9 \mathrm{~m}^{2} / \mathrm{M}^{2}[16,17]\right) ; b_{e(i+1)}-$ width of the passage or door when moving into $(i+1)$-zone, $\mathrm{m}$.

The evacuation path $l_{e, j}$ is defined as the diagonal of the rectangular $j$-area of the human passage in the object's premises, that is

$l_{e . j}=k_{c} \sqrt{L_{j}^{2}+B_{j}^{2}}, \mathrm{~m}$,

where $k_{c}=1,4$ - coefficient which takes into account the curvature of the evacuation pathway in zone of fire; $L_{j}-$ length of the $j$-th passage in zone of fire, $\mathrm{m} ; B_{j}$ - width of the passage, $\mathrm{m}$.

Average speed:

- on a horizontal path, through the aisle and down the stairs can be determined by dependence [17]

$V_{e . j}=49,5-9,27 \ln \left[-\lg \left(0,1+1,284 k_{e m . j}\right)\right]$;

- in the case of movement by stairs upwards

$V_{e . j}=26,75-6,36 \ln \left[-\lg \left(0,1+1,284 k_{e m . j}\right)\right]$,

where $k_{e m . j}$ - coefficient that takes into account the emotional state of evacuated people in the $j$-th passage; the value of this coefficient is within $k_{e m . j}=0 \ldots 0,7$ (in the absence of information about the emotional state of people $k_{\text {em.j }}=0$ ) [17].

In order to determine the true average speed of movement, it is necessary to take into account the density of the human flow $D_{e, j}\left(\mathrm{~m}^{2} / \mathrm{m}^{2}\right)$, which is determined by the dependence

$D_{e . j}=\frac{N_{e . j} S}{l_{e . j} b_{e . j}}$,

where $N_{e . j}$ - number of people on the evacuation path $l_{e . j}$; $b_{e, j}$ - width of aisle or door at exit from $j$-area, $\mathrm{m}$.

In this case, the actual speed of movement of the human stream $V_{\text {e.j.a }}$ will be determined by dependence 
$V_{e . j . a}=V_{e . j} k_{D}$

The value of $k_{D}$ is determined by the dependence

$k_{D}=0,98 \exp \left(-2,11 D_{e . j}\right)$.

In addition, the density of the human flow $D_{e, j}$ influences the intensity of its movement $q_{e . j}(\mathrm{~m} / \mathrm{min})$. Therefore, it is necessary to validate the actual value of $q_{e . j}$ with the admissible $[q]$ using the dependence

$q_{e . j}=44,38 D_{e . j}^{2}+51,6 D_{e . j}+2,27 \leq[q]$,

where $[q]=16,5 \mathrm{~m} / \mathrm{min}$ - for a horizontal path; $[q]=19,6 \mathrm{~m} /$ $\min$ - for doorways; $[q]=16 \mathrm{~m} / \mathrm{min}$ - for movement by stairs down; $[q]=11 \mathrm{~m} / \mathrm{min}$ - for movement by stairs upwards.

In the case where $q_{e . j} \leq[q]$, the actual speed of movement is determined by Eq. (19), and in the case when $q_{e . j}$ $>[q]$ the actual speed of movement is determined at $D_{e, j}=$ $0,9 \mathrm{~m}^{2} / \mathrm{M}^{2}$.

When determining the probability of evacuation of people $P_{\text {e.n.i }}$ by evacuation routes in the zone of the occurrence of fire by Eq. (11), it is necessary to take into account the following provisions:

1. in the case where $\tau_{e . i}<0,8 \cdot \tau_{c}<\tau_{e . i}+\tau_{\text {ne. } i}$, then $P_{e . n . i}$ are determined by the dependence (11);

2. in the case where $\tau_{e . i}+\tau_{\text {n.e. }} \leq 0,8 \cdot \tau_{c}$, then $P_{\text {e.n.i }}=0,999$;

3 . in the case where $\tau_{e . i} \geq 0,8 \cdot \tau_{c}$, then $P_{e . n . i}=0$.

The average value of the victims $N_{i}$ in zone of fire from its dangerous factors can be determined by dependence

$N_{i}=\sum_{i=1}^{I} P_{i} n_{i}$

where $P_{i}$ - conditional probability of injury of a person located in $i$-zone, dangerous factors of fire; $n_{i}$ - the average number of people who are in $i$-zone; $I$ - the total number of zones in which the fire occurred.

To determine $P_{i}$ it is necessary to know the probability of evacuation of people $P$ from zone of operation of dangerous fire factors, which in turn depends on the critical time of fire $\tau_{c}$, the time of evacuation $\tau_{e . i}$, and the interval of time from the beginning of fire to the start of evacuation from $i$-zone $\tau_{\text {n.e.i }}$. On this

$P=1-P_{e}$

After developing a method for determining the probability of evacuating people from the zone of exposure to dangerous fire factors, consider an example based on the assembly workshop of a woodworking enterprise in the Lviv region, Ukraine (Fig. 2).

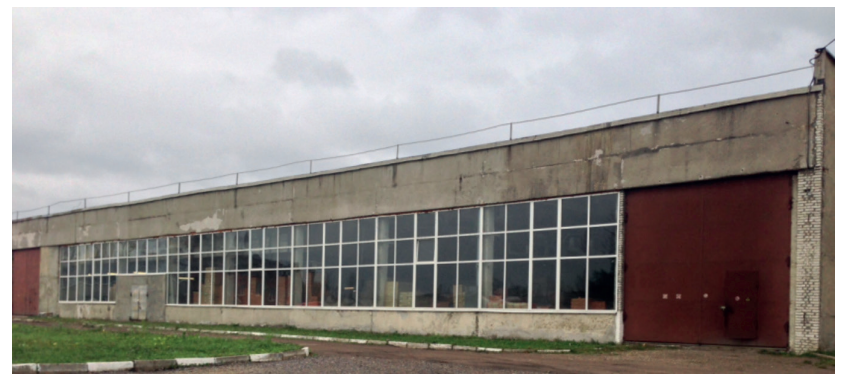

Fig. 2 Facade of assembly workshop of woodworking enterprise

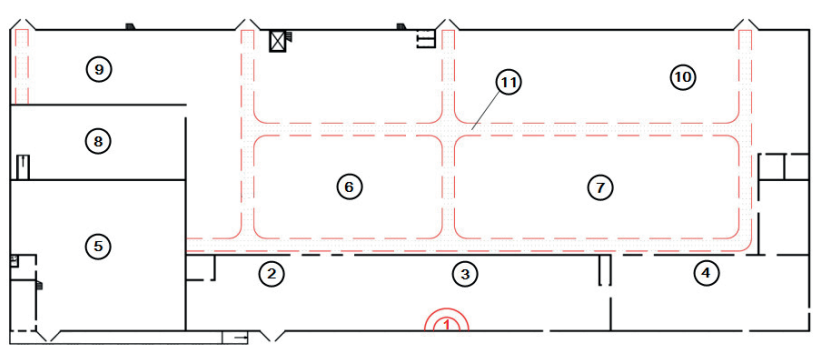

Fig. 3 Plan of the assembly workshop of the woodworking enterprise: 1 - place of fire starting; 2 - painting section; 3 - varnishing section; 4 - facing section; 5 - finished product warehouse; 6 - packing section; 7 machining section; 8 - place of storage of finished products; 9 - refinement section; 10 - place of storage of raw materials;

$$
11 \text { - main passages }
$$

\subsection{Example}

Output data: determine the probability of a successful evacuation of people in the event of an angular fire $\left(180^{\circ}\right)$ in the lacquer unit (the location of fire 1 is shown in Fig. 3. General characteristics of the workshop: the area of the premises is $14256 \mathrm{~m}^{2}$; height of the workshop - $6 \mathrm{~m}$; the volume of premises $-85536 \mathrm{~m}^{3}$; length of the workshop - $192 \mathrm{~m}$; distance between columns - $6 \mathrm{~m}$; width of the workshop - $72 \mathrm{~m}$; fire load $-200 \mathrm{~kg} / \mathrm{m}^{2}$. The enclosing structures of the walls between the compartments are made of bricks. The total number of emergency exits -6 , and working in one shift - 152 people. The general view of the workshop is shown in Fig. 2, and the layout plan of the workshop is shown in Fig. 3.

The merging of evacuation flows is carried out on the main aisles $b_{e . i}=4 \mathrm{~m}$ wide, located on the longitudinal and transverse spans of the workshop (Fig. 3). The width of the evacuation doors is $b_{e . i}=4 \mathrm{~m}$, which provide an exit to the platform $b_{e(i+1)}=4 \mathrm{~m}$ wide. The time from the start of fire to the start of the evacuation is $\tau_{n . e . i}=2$ minutes (the workshop is equipped with a fire protection system). The emotional state of people is taken into account by a coefficient $k_{\text {em.j. }}=0,35$. 


\subsection{Solution}

1 Determination of the critical time of fire $\tau_{c}$

1) by the concentration of oxygen for circular development of fire by Eq. (2):

$$
\tau_{c . O_{2}}=\sqrt[3]{1442 V}=\sqrt[3]{1442 \cdot 85536}=495, \mathrm{~s} ;
$$

2) by concentration of $\mathrm{CO}_{2}$ by Eq. (5):

$$
\tau_{c . \mathrm{CO}_{2}}=\sqrt[3]{6794 \cdot 85536 \cdot \ln \left(\frac{1}{1-\frac{35,9}{0,203} 0,11}\right)}=1192, s ;
$$

3) by concentration of CO by Eq. (5):

$$
\tau_{c . C O}=\sqrt[3]{6794 \cdot 85536 \cdot \ln \left(\frac{1}{1-\frac{35,9}{0,0022} 0,00116}\right)}=1188, s ;
$$

4) by concentration of $\mathrm{HCl}$ by Eq. (5):

$$
\tau_{c . H C l}=\sqrt[3]{6794 \cdot 85536 \cdot \ln \left(\frac{1}{1-\frac{35,9}{0,014} 0,000023}\right)}=328, s ;
$$

5) on basis of the smallest value $\tau_{c}$, one determines the optical density of smoke by Eq. (8):

$$
\mu=7,5\left[1-\exp \left(-\frac{3,5 \cdot 10^{-5} \cdot 1,57 \cdot 328^{3}}{85536}\right)\right]=0,17 \mathrm{~Np} / \mathrm{m}<1,2 \mathrm{~Np} / \mathrm{m}
$$

$6)$ one determines the temperature of the room environment heating by Eq. (9) at $k=0,07$ :

$t=[345 \cdot \lg (8 \cdot 5,5+1)] 0,07+20=60^{\circ} \mathrm{C}$, which is permissible.

To confirm the predicted temperature $t=60^{\circ} \mathrm{C}$, mathematical models and a computer program developed in the Lviv State University of Life Safety [18] were used. Analysis of the results of computer simulation of isotherms in the vertical section of the workshop at a height of $6000 \mathrm{~mm}$ for $6 \mathrm{~min}$ at the outlet of the workshop from the painting section showed that the heating room temperature of the workshop room at an altitude of up to $2 \mathrm{~m}$ from the floor level does not exceed $58^{\circ} \mathrm{C}$.

On the basis of the results, one obtains the critical time of fire $\tau_{c}=5,5 \mathrm{~min}(328 \mathrm{~s}$ ). During this time the fire spread through the lacquer and painting sections. To confirm this forecast, the FDS program [2] was used. The results of simulation of the fire spread in the assembly workshop using the FDS program are shown in Fig. 4.

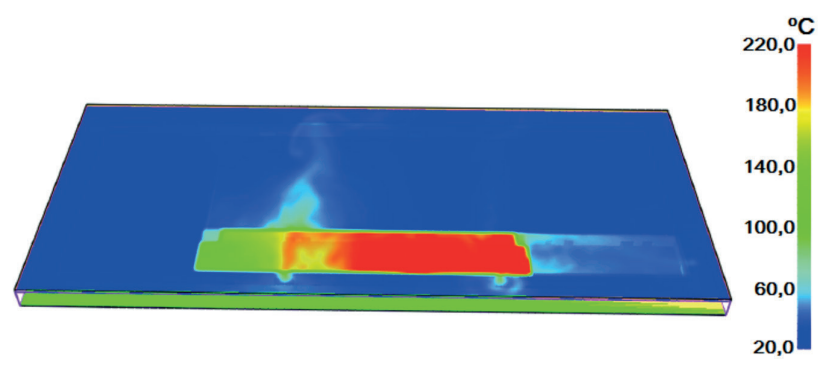

Fig. 4 Results of simulation of the FDS program for the development of the angular fire $\left(180^{\circ}\right)$ in the lacquer and painting sections for 5,5 $\mathrm{min}$

\section{Determination of evacuation time}

1) determination of speed of people in sections of $i$-zone on a horizontal path by Eq. (16):

$V_{e . j}=49,5-9,27 \ln [-\lg (0,1+1,284 \cdot 0,35)]=62 \mathrm{~m} / \mathrm{min}$;

2) determination of the density of the human stream $D_{e . j}$ at the exit on the main passages of the workshop with a length of follow-up of $70 \mathrm{~m}$, with a width of $4 \mathrm{~m}$ and 4 streams of 38 people:

$$
\begin{aligned}
& l_{e . j}=1,4 \sqrt{70^{2}+4^{2}}=98 \mathrm{~m} ; \\
& D_{e . j}=\frac{38 \cdot 0,125}{98 \cdot 4}=0,012 \mathrm{~m}^{2} / \mathrm{m}^{2} ;
\end{aligned}
$$

3) determination of the actual speed of the human stream by Eq. (19) and the value of coefficient $k_{D}$ by Eq. (20):

$$
k_{D}=0,98 \exp (-2,11 \cdot 0,012)=0,95 \text {; }
$$$$
V_{e . j . a}=62 \cdot 0,95=58,9 \mathrm{~m} / \mathrm{min} \text {; }
$$

4) checking the actual value $q_{e . j}$ for the horizontal path with the admissible $[q]$ by Eq. (21):

$$
\begin{aligned}
& q_{e . j}=44,38 \cdot 0,012^{2}+51,6 \cdot 0,012+2,27=2,9 \mathrm{~m} / \mathrm{min} ; \\
& q_{e . j}=2,9 \mathrm{~m} / \min <[q]=16,5 \mathrm{~m} / \mathrm{min} ;
\end{aligned}
$$

5) determination of the time of evacuation with the simultaneous use of 4 evacuation exits with the length of the evacuation path for each exit $98 \mathrm{~m}$ and a speed of $58,9 \mathrm{~m} / \mathrm{min}$ :

$\tau_{e . j}=\frac{98}{4 \cdot 58,9}=0,42 \mathrm{~min}$

6) determination of the probable delay time (the values $q_{e . i}=2,9 \mathrm{~m} / \mathrm{min}$ and $q_{e(i+1)}=2 \mathrm{~m} / \mathrm{min}$ in accordance with the recommendations [16] and $b_{e(i+1)}=4 \mathrm{~m}$ were taken): $\tau_{d . V}=38 \cdot 0,125\left(\frac{1}{2 \cdot 4}-\frac{1}{2,9 \cdot 4}\right)=0,19 \mathrm{~min} ;$

In this case, the time of evacuation will be $\tau_{e . i}=\tau_{e . j}+\tau_{d . i}=0,42+0,19 \approx 1 \mathrm{~min}$. 
3 Determination of the probability of people evacuation who are in i-zone by Eq. (11):

$$
P_{e . n . V}=\frac{0,8 \cdot 5,5-1}{2}>1,
$$

which ensures the successful evacuation of people from the workshop where the fire occurred.

In case of absence of firefighting equipment in the workshop, in particular fire alarm and other equipment, the overall probability of evacuation of people with average time of the start of evacuation $\tau_{\text {n.e. }}=3,5$ min will be equal to $P_{e, n . i}=0,97$. Then

$$
P_{e}=1-(1-0,97)(1-0,001)=0,97003 .
$$

In this case, the number of affected $N_{i}$ in zone of fire from the influence of its dangerous factors are determined by Eq. (22):

$$
N_{i}=152(1-0,97003) \approx 5 \text { people. }
$$

The engineering method of determining the critical time of fire and determining the probability of evacuation of people from zone of fire was tested in practice for developing operational firefighting plans for different enterprises. The parameters determined by this method are adequate and confirmed by other methods of calculation $[2,18]$. The results of the comparison are presented in an example.

\section{Conclusions}

1. The engineering method of determining the critical time of fire and determining the probability of evacuation of people from zone of fire was developed, which makes it possible, with simplified dependencies, to quickly determine all necessary factors in the process of evacuation of people in case of fire in the building.

2. The introduction of method of determining the critical time of fire and determining the probability of evacuation of people from zone of fire allows to include these parameters in operational firefighting plans for various objects, which will greatly facilitate the management of the evacuation process by the administration of enterprises.

3. The parameters determined by this method are adequate and confirmed by other methods of calculation, in particular, by methods $[2,18]$. The relative error between the specified parameters does not exceed $8 \ldots 12 \%$ (in comparison with other mentioned methods $[2,18])$.

\section{References}

[1] Koshmarov, Yu. А. "Прогнозирование опасных факторов пожара в помещении", (Forecasting of dangerous fire factors in the building), Academy of State Fire Service, Moscow, Russia, 2000. (in Russian)

[2] SITIS "Рекомендации по использованию программы FDS с применением программ PyroSim2012, SmokeView и «СИТИС: Фламмер»", (Recommendations for using the FDS program with PyroSim2012, SmokeView and SITIS: Flammer), Sitis, Ekaterinburg, Russia, 2012. (in Russian)

[3] Welch, S., Rubini, P. "SOFIE: Simulations of Fires in Enclosures, User Guide", Cranfield University, South England, United Kingdom, 1996.

[4] Puzach, S. V. "Методы расчета тепломассообмена при пожаре в помещении и их применение при решении практических задач пожаровзрывобезопасности", (Methods for calculating heat and mass transfer during a fire in a building and their application in solving practical fire and explosion safety problems), Academy of State Fire Service, Moscow, Russia, 2005. (in Russian).

[5] Zheng, Y., Jia, B., Li, X.-G., Zhu, N. "Evacuation dynamics with fire spreading based on cellular automaton", Physica A: Statistical Mechanics and its Applications, 390(18-19), pp. 3147-3156, 2011. https://doi.org/10.1016/j.physa.2011.04.011

[6] Cao, S.-C., Song, W.-G., Liu, X.-D., Mu, N. "Simulation of pedestrian evacuation in a room under fire emergency", Procedia Engineering, 71, pp. 403-409, 2014.

https://doi.org/10.1016/j.proeng.2014.04.058

[7] Yang, P., Li, C., Chen, D. "Fire emergency evacuation simulation based on integrated fire-evacuation model with discrete design method", Advances in Engineering Software, 65, pp. 101-111, 2013.

https://doi.org/10.1016/j.advengsoft.2013.06.007

[8] Liu, X.-D., Song, W.-G., Huo, F.-Z., Jiang, Z.-G. "Experimental study of pedestrian flow in a fire-protection evacuation walk", Procedia Engineering, 71, pp. 343-349, 2014. https://doi.org/10.1016/j.proeng.2014.04.049

[9] Lujak, M., Giordani, S. "Centrality measures for evacuation: Finding agile evacuation routes", Future Generation Computer Systems, 83, pp. 401-412, 2018.

https://doi.org/10.1016/j.future.2017.05.014

[10] Zheng, Y., Jia, B., Li, X.-G., Jiang, R. "Evacuation dynamics considering pedestrians' movement behavior change with fire and smoke spreading", Safety Science, 92, pp. 180-189, 2017. https://doi.org/10.1016/j.ssci.2016.10.009

[11] Nguyen, M. H., Ho, T. V., Zucker, J.-D. "Integration of Smoke Effect and Blind Evacuation Strategy (SEBES) within fire evacuation simulation", Simulation Modelling Practice and Theory, 36, pp. 44-59, 2013.

https://doi.org/10.1016/j.simpat.2013.04.001

[12] Kasereka, S., Kasoro, N., Kyamakya, K., Goufo, E.-F. D., Chokki, A. P., Yengo, M. V. "Agent-Based Modelling and Simulation for evacuation of people from a building in case of fire", Procedia Computer Science, 130, pp. 10-17, 2018. https://doi.org/10.1016/j.procs.2018.04.006 
[13] Tang, F., Ren, A. "GIS-based 3D evacuation simulation for indoor fire", Building and Environment, 49, pp. 193-202, 2012. https://doi.org/10.1016/j.buildenv.2011.09.021

[14] Liu, S.-J., Zhu, G.-Q. "The application of GIS and IOT technology on building fire evacuation", Procedia Engineering, 71, pp. 577582,2014

https://doi.org/10.1016/j.proeng.2014.04.082

[15] Hulida, E. М. "Прогнозування величини оптичної густини диму при пожежі в приміщені", (Forecasting of the optical density of smoke during a fire in the building), Fire Safety, 18, pp. 65-70, 2011. (in Ukrainian)
[16] Samoshin, D. A. "Расчет пожарных рисков для общественных, жилых и административных зданий", (Calculation of fire risks for public, residential and office buildings), Academy of State Fire Service, Moscow, Russia, 2010. (in Russian)

[17] Holschevnikov, V. V. "Моделирование людских потоков", (Modeling of human flows), Modeling of Fires and Explosions, 1, pp. 139-169, 2000. (in Russian)

[18] Hulida, E. M., Koval, O. М. "Моделювання пожежних ситуацій в приміщеннях будівель деревообробних підприємств", (Modeling of fire situations in buildings of woodworking enterprises), Fire safety Problems, 35, pp. 61-77, 2014. (in Ukrainian) 